\title{
RESEARCH
}

Open Access

\section{Value of vessel wall magnetic resonance imaging in the diagnosis of cerebrovascular diseases}

Sherien Farag ${ }^{1}$, Hany Zaki El-Dien', Yasser Abdelazeem², Mohammed Khaled Elewa' ${ }^{1}$, Khaled Abdelmaksoud ${ }^{1}$ and Ahmed ElSadek ${ }^{1 *}$

\begin{abstract}
Background: Intracranial vessel wall imaging can detect non-stenotic lesions with further characterization of stenotic lesions that have already been detected with common angiographic methods. Magnetic resonance imaging (MRI) of the intracranial vessel wall can describe the presence of both large and small atherosclerotic lesions and to characterize the lesions based on enhancement, plaque content, and vulnerability

Objectives: To assess suspicious lesions detected by magnetic resonance angiography for further evaluation by vessel wall MRI.

Methods: A total of sixteen ischemic stroke patients within 2 weeks from onset were recruited to this crosssectional study. Magnetic resonance angiography was done to document intracranial arterial stenosis. Further highfield MR unit (3 Tesla MRI Scanner) was used to obtain vessel wall MR sequences (T1 pre-post contrast and T2 fat sat) to differentiate between intracranial atherosclerotic plaque, vasculitis, and moyamoya disease and to assess atherosclerotic plaque activity (vulnerability)

Results: Vessel wall MR imaging showed arterial wall thickening with irregular inner margin and eccentric enhancement in cases of intracranial atherosclerosis, where as in case of CNS vasculitis, it showed circumferential wall enhancement with regular smooth inner margin. In cases of moyamoya disease, the vessel wall MR showed a narrowing of the luminal artery without post-contrast enhancement of the wall, no hemorrhagic nor fatty content.
\end{abstract}

Conclusion: Vessel wall MR imaging is recommended for stroke patients with suspected intracranial large vessel atherosclerosis seen in MRA to assess atherosclerotic plaque activity and characterization of stenotic lesions

Keywords: Vessel wall magnetic resonance imaging, Atherosclerotic plaque, Intracranial vessel wall

\footnotetext{
* Correspondence: ahmedelsadek_79@yahoo.com

${ }^{1}$ Neurology Department, Ain Shams University, 19/1/42 Elrehab City, Cairo

11841, Egypt

Full list of author information is available at the end of the article
}

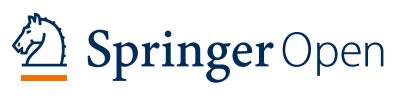

(c) The Author(s). 2020 Open Access This article is licensed under a Creative Commons Attribution 4.0 International License, which permits use, sharing, adaptation, distribution and reproduction in any medium or format, as long as you give appropriate credit to the original author(s) and the source, provide a link to the Creative Commons licence, and indicate if changes were made. The images or other third party material in this article are included in the article's Creative Commons licence, unless indicated otherwise in a credit line to the material. If material is not included in the article's Creative Commons licence and your intended use is not permitted by statutory regulation or exceeds the permitted use, you will need to obtain permission directly from the copyright holder. To view a copy of this licence, visit http://creativecommons.org/licenses/by/4.0/. 


\section{Introduction}

Accurate diagnosis of intracranial vasculopathies is important to avoid the risk of morbidity with incorrect diagnosis both from the disease process as well as insufficient therapies [1]. Conventional techniques for imaging the intracranial arteries as computed tomography angiography (CTA) and magnetic resonance angiography (MRA) can detect abnormalities of the vessel lumen, but they cannot characterize different pathologies within the vessel wall [2]. The main advantages of intracranial vessel wall imaging over lumenbased methods are the detection of non-stenotic lesions and further characterization of stenotic lesions that have already been detected with conventional angiographic methods [3]. Intracranial vessel wall imaging by MRI should be able to describe the presence of both large and small (atherosclerotic) lesions and to characterize the lesions with respect to enhancement, plaque content, and vulnerability [4].

Considering the need for high-resolution and adequate signal-to-noise for the evaluation of small, tortuous arteries, intracranial vessel wall scans can be timeconsuming, which can be a limiting factor for a wide use due to its impact on patient throughput, limited quality due to patient motion and patient discomfort [5].

Our study aims to assess suspicious lesions detected by magnetic resonance angiography for further evaluation by vessel wall MRI.

\section{Methods}

A total of sixteen ischemic stroke patients within 2 weeks from onset were recruited during the period from November 2018 to May 2019 to this cross-sectional pilot study. Patients with ischemic stroke within 2 weeks from onset were detected by magnetic resonance imaging (MRI) and have intracranial artery stenosis seen in magnetic resonance angiography (MRA). All ages and both sex were included. Patients who had contraindications for undergoing MRI scans as metallic implants (heart pacemaker, prosthetic heart valves, foreign body in the eye, cochlear implant) and patients with renal impairment were excluded from this study.

All patients were evaluated clinically with complete medical and neurological history and examination, and baseline laboratory investigations (renal function test, lipid profile, and erythrocyte sedimentation rate). Neuroimaging was done including MRI brain (Philips 1.5 Tesla, Japan) (diffusion-weighted, Flair, T1, T2, and $\mathrm{T}_{2}^{*}$ images) and magnetic resonance angiography. Further evaluation of intracranial vessels was done using vessel wall magnetic resonance imaging.

A high-field MR unit (3 Tesla MRI Scanner) was used to obtain vessel wall MR sequences ( $\mathrm{T} 1$ pre-post contrast and $\mathrm{T} 2$ fat sat) in order to differentiate between intracranial atherosclerotic plaque, vasculitis, and moyamoya disease and to assess atherosclerotic plaque activity (vulnerability). Vulnerable plaque is an active inflammatory plaque that shows post-contrast enhancement or plaque with hemorrhagic content. Non-vulnerable plaque is a plaque without active inflammation and no postcontrast enhancement nor hemorrhagic content.

Patients were divided according to type of intracranial vasculopathies into 3 groups, intracranial atherosclerotic (ICAD) group, CNS vasculitis group, and moyamoya disease group.

Written informed consent approved by ethical committee of our institute was obtained from the patients participating in the study, or their first-degree relatives if the patient was unable to provide consent due to weakness or disturbed conscious level, after informing them about the study rationale and their right to withdraw from the study at any time without any consequences.

\section{Statistical analysis}

Data were coded and entered using the Statistical Package for the Social Sciences (SPSS) version 25 (IBM Corp., Armonk, NY, USA). Data was summarized using the mean, standard deviation, median, minimum, and maximum in quantitative data and using frequency (count) and relative frequency (percentage) for categorical data. Comparisons between quantitative variables were done using non-parametric Kruskal-Wallis and Mann-Whitney tests [6]. For comparing categorical data,

Table 1 Demographic and baseline characteristics of the study population

\begin{tabular}{|c|c|c|c|}
\hline & & Number & $\%$ \\
\hline \multirow[t]{3}{*}{ Group } & Atherosclerotic & 11 & 68.8 \\
\hline & Vasculitis & 3 & 18.8 \\
\hline & Moyamoya & 2 & 12.5 \\
\hline \multirow[t]{2}{*}{ Sex } & Male & 9 & 56.3 \\
\hline & Female & 7 & 43.8 \\
\hline \multirow[t]{2}{*}{ Hypertension } & Yes & 11 & 68.8 \\
\hline & No & 5 & 31.3 \\
\hline \multirow[t]{2}{*}{ Diabetes mellitus } & Yes & 7 & 43.8 \\
\hline & No & 9 & 56.3 \\
\hline \multirow[t]{2}{*}{ Ischemic heart disease } & Yes & 5 & 31.3 \\
\hline & No & 11 & 68.8 \\
\hline \multirow[t]{2}{*}{ Atrial fibrillation } & Yes & 1 & 6.3 \\
\hline & No & 15 & 93.8 \\
\hline \multirow[t]{2}{*}{ Old cerebrovascular disease } & Yes & 1 & 6.3 \\
\hline & No & 15 & 93.8 \\
\hline \multirow[t]{2}{*}{ Smoking } & Yes & 5 & 31.3 \\
\hline & No & 11 & 68.8 \\
\hline
\end{tabular}


Table 2 Comparison between groups regarding significant intracranial stenosis

\begin{tabular}{|c|c|c|c|c|c|c|c|c|}
\hline & & \multicolumn{6}{|l|}{ Group } & \multirow{3}{*}{$P$ value } \\
\hline & & \multicolumn{2}{|c|}{ Atherosclerotic } & \multicolumn{2}{|c|}{ Vasculitis } & \multicolumn{2}{|c|}{ Moyamoya } & \\
\hline & & Count & $\%$ & Count & $\%$ & Count & $\%$ & \\
\hline \multirow[t]{2}{*}{ Significant intracranial stenosis ( $>50 \%$ ) } & Yes & 9 & 81.8 & 0 & 0.0 & 2 & 100.0 & 0.025 \\
\hline & No & 2 & 18.2 & 3 & 100.0 & 0 & 0.0 & \\
\hline
\end{tabular}

chi-squared $(x 2)$ test was performed. Fisher's exact test was used instead when the expected frequency is less than 5. $P$ values less than 0.05 were considered as statistically significant [7].

\section{Results}

Sixteen patients were included to this study: 9 (56.3\%) males and 7 (43.8\%) females. The age of patients ranged from 18 to 80 years with a mean age of 49.38 . The most prevalent risk factor was hypertension, being present in 11 patients representing $68.8 \%$ of the study population. Diabetes mellitus was found in $7(43.8 \%)$ patients. Regarding the cardiac diseases, 5 (31.3\%) patients gave history of ischemic heart disease, 1 (6.3\%) had atrial fibrillation, and 5 (31.3\%) patients gave history of smoking. History of previous ischemic stroke was found in 1 (6.3\%) patient (Table 1).

The results showed a statistically significant difference between groups as regard the age. Intracranial atherosclerosis was common in elderly patients whereas cases of CNS vasculitis and moyamoya disease were more prevalent among younger ages.
Comparing groups regarding the significant intracranial stenosis $(>50 \%)$ revealed that significant stenosis was prominent among moyamoya disease group (100.0\%) followed by intracranial atherosclerotic groups (81.8\%), whereas CNS vasculitis group shows mild intracranial stenosis $(0.0 \%)$ (Table 2).

As regard the findings of different intracranial vasculopathy on vessel wall MR, Table 3 shows those findings among the three studied groups.

MR vessel wall imaging significantly improves imaging diagnostic differentiation of intracranial vasculopathies in $100 \%$ of the studied cases while MRA cannot (Table 4) (Figs. 1, 2, and 3).

In cases of atherosclerosis, MR vessel wall imaging can detect a plaque activity (vulnerability) in 100\% of studied cases whereas MRA cannot (Table 5) (Fig. 3). Vessel wall MR imaging criteria for different intracranial vasculopathies in the cases studied are summarized in Table 6.

Among the intracranial atherosclerotic group (11 cases), 8 cases showed a plaque activity whereas 3 cases showed inactive one (Fig. 4).

Table 3 Intracranial vessel wall imaging findings among the study groups

\begin{tabular}{|c|c|c|c|c|c|c|}
\hline Vessel wall imaging criteria & $\begin{array}{l}\text { Arterial wall } \\
\text { thickening }\end{array}$ & $\begin{array}{l}\text { luminal } \\
\text { narrowing }\end{array}$ & $\begin{array}{l}\text { Inner margin } \\
\text { (regular vs irregular) }\end{array}$ & $\begin{array}{l}\text { Shape (eccentric } \\
\text { vs concentric) }\end{array}$ & $\begin{array}{l}\text { Post-contrast } \\
\text { enhancement }\end{array}$ & $\begin{array}{l}\text { Hemorrhagiccomponent/ } \\
\text { hematoma }\end{array}$ \\
\hline \multirow{8}{*}{$\begin{array}{l}\text { Vulnerable atherosclerosis } \\
\text { (8 cases) }\end{array}$} & + & + & Irregular & Eccentric & Eccentric & Yes \\
\hline & +++ & ------ & Irregular & Eccentric & Eccentric & Yes \\
\hline & + & ++ & Irregular & Eccentric & Eccentric & No \\
\hline & ----- & ++ & ------- & Eccentric & Eccentric & No \\
\hline & ++ & +++ & Irregular & --------- & Eccentric & Yes \\
\hline & ------ & + & Irregular & Eccentric & Eccentric & No \\
\hline & ------ & + & & Eccentric & Eccentric & No \\
\hline & ++ & ------ & Irregular & Eccentric & Eccentric & Yes \\
\hline \multirow{3}{*}{$\begin{array}{l}\text { Non-vulnerable } \\
\text { atherosclerosis ( } 3 \text { cases) }\end{array}$} & ++ & ++ & Irregular & Eccentric & No & No \\
\hline & +++ & +++ & Irregular & ---------- & No & No \\
\hline & + & + & ------- & Eccentric & No & No \\
\hline \multirow[t]{3}{*}{ CNS vasculitis ( 3 cases) } & + & -------- & Regular & Concentric & Circumferential & No \\
\hline & ------ & ------- & Regular & Concentric & Circumferential & No \\
\hline & Variable & & Regular & Concentric & Circumferential & No \\
\hline \multirow[t]{2}{*}{ Moyamoya disease ( 2 cases) } & 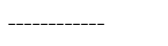 & ++++ & -------- & 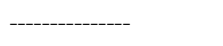 & No & No \\
\hline & 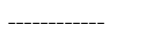 & ++++ & 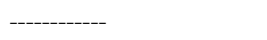 & - & No & No \\
\hline
\end{tabular}


Table 4 Comparison between MRA and MR vessel wall imaging in the ability to differentiate vessel wall pathology among the studied cases

\begin{tabular}{|c|c|c|c|c|c|}
\hline \multicolumn{2}{|l|}{ Vessel wall pathology differentiation } & \multicolumn{4}{|c|}{ MR vessel wall imaging } \\
\hline & & \multicolumn{2}{|c|}{ Yes } & \multicolumn{2}{|c|}{ No } \\
\hline & & Count & $\%$ & Count & $\%$ \\
\hline \multirow[t]{2}{*}{ Magnetic resonance angiography } & Yes & 0 & 0 & 0 & 0 \\
\hline & No & 16 & 100 & 0 & 0 \\
\hline
\end{tabular}

\section{Discussion}

The primary objective of this study was to assess suspicious lesions detected by magnetic resonance angiography (MRA) for further evaluation by vessel wall MRI. This study was conducted on 16 patients who were admitted to our hospital with established diagnosis of stroke (11 patients with intracranial atherosclerosis, 3 patients with CNS vasculitis, and 2 patients with moyamoya disease) performing MRI brain including magnetic

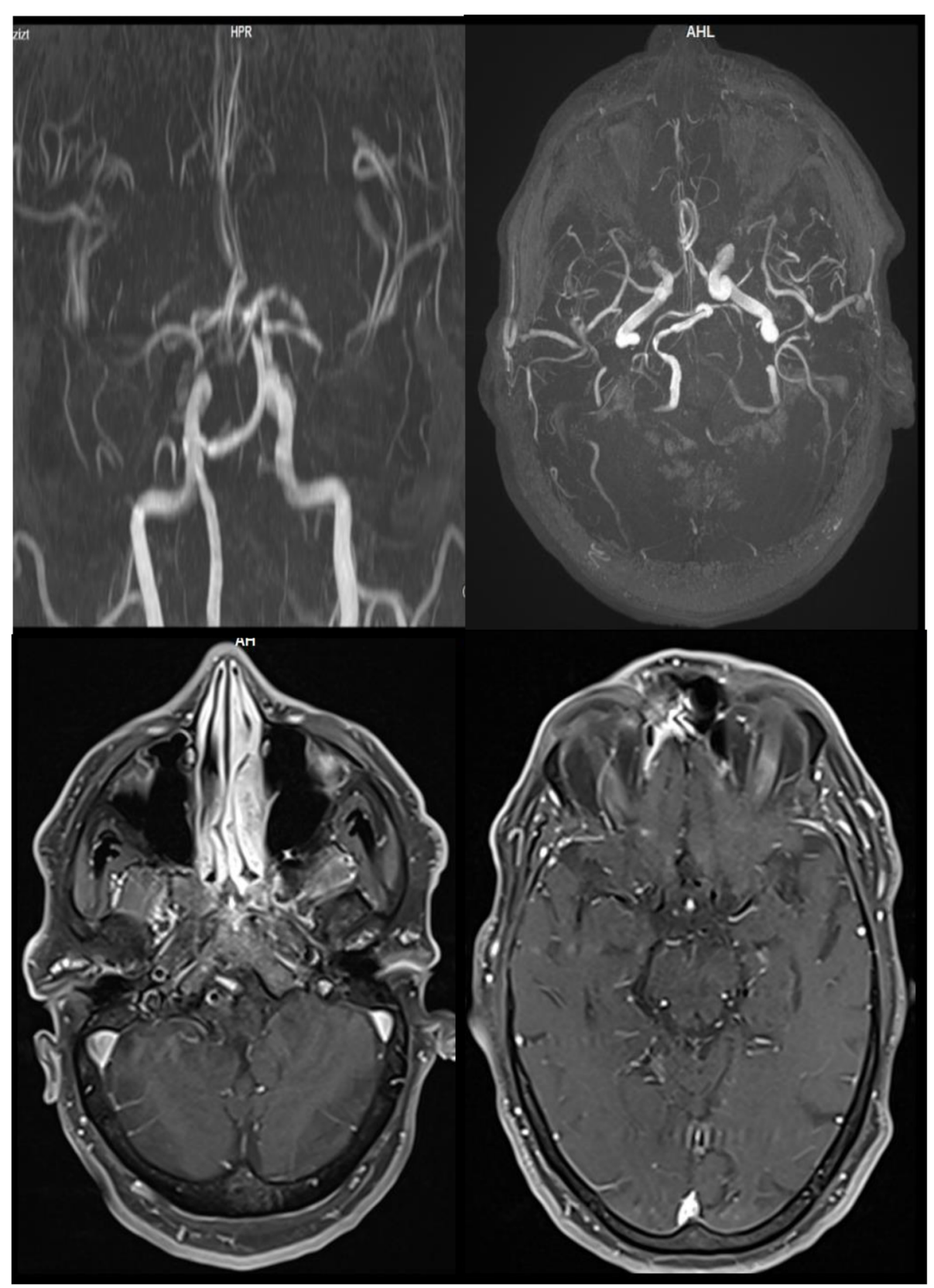

Fig. 1 MRA shows diffuse atherosclerotic changes and attenuations mainly Lt MCA (a) and Rt vertebral art (b). MR vessel wall imaging shows eccentric wall thickening with enhancement and irregular inner margin of Rt vertebral (c) and Lt MCA (d). Such MR vessel wall pattern is suggestive of vulnerable atherosclerotic plaque 


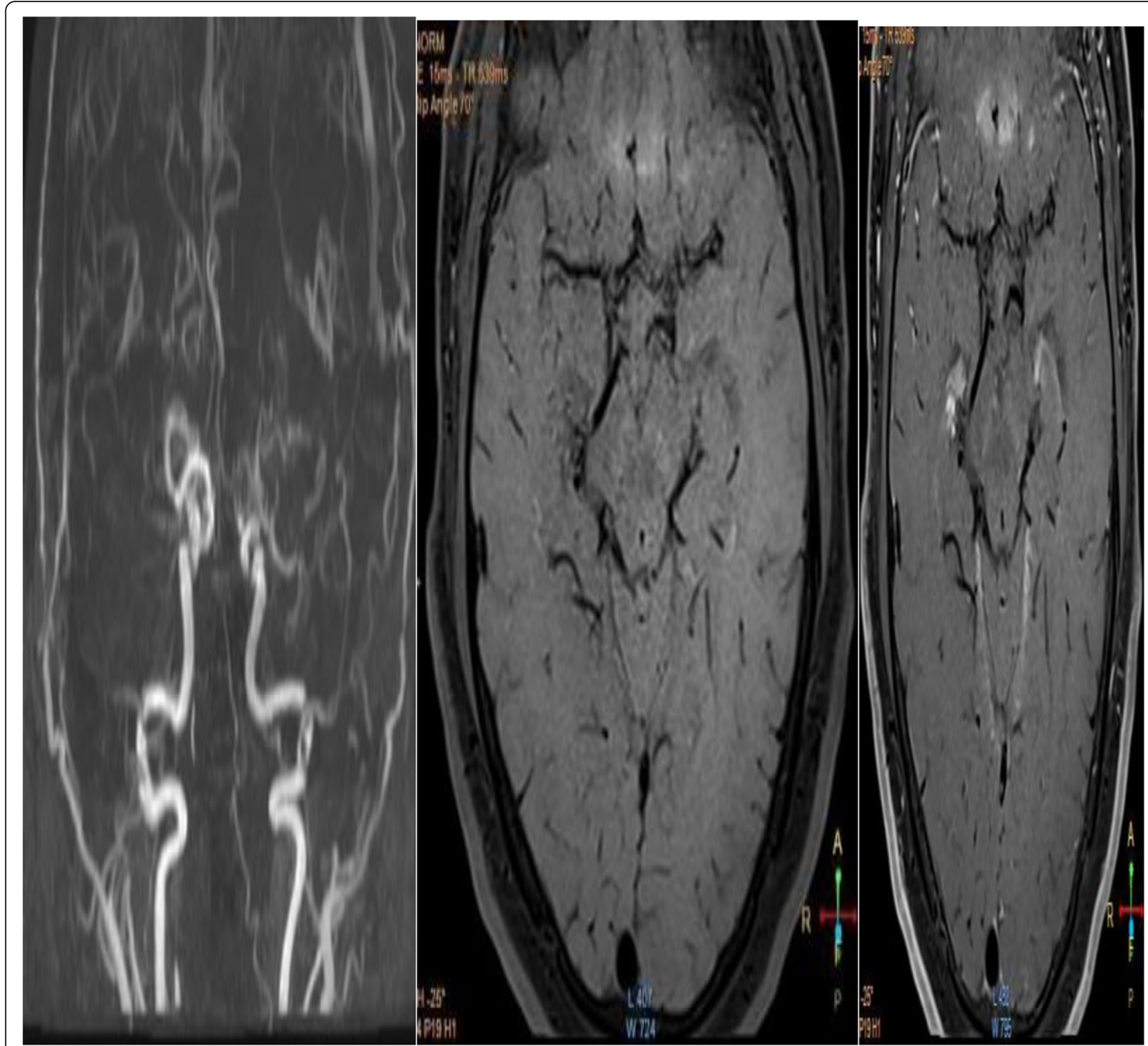

Fig. 2 MRA shows remarkable stenosis of the cavernous and supraclenoid parts of both ICA as well as their main branches of both MCA and ACA (A). MR vessel wall imaging demonstrated a remarkable attenuation, narrowing of MCA and ACA [axial pre (B1), and post (B2) contrast] bilaterally, yet no abnormal post-contrast enhancement of the wall and no hemorrhagic nor fatty content; this is going with Moya-Moya disease for a patient who had already done a diagnostic cerebral angiography giving a picture of puff of smoke appearance

resonance angiography (MRA) that showed intracranial stenosis. Further evaluation of intracranial vasculopathies by vessel wall MR imaging using 3.0-tesla (T) field strengths. Vessel wall MR imaging showed arterial wall thickening with irregular inner margin and eccentric (nonuniformly) enhancement in cases of intracranial atherosclerosis, whereas in case of CNS vasculitis, it showed circumferential (uniformly) wall enhancement with regular smooth inner margin. In cases of moyamoya disease, vessel wall MR showed a narrowing of the luminal artery without post-contrast enhancement of the wall, no hemorrhagic nor fatty content.
In cases of intracranial atherosclerosis, a narrowed luminal artery, wall thickening with irregular inner margin, eccentric (non-uniformly) enhancement, or hemorrhagic component, these vessel wall imaging criteria point out to activity (vulnerability) of atherosclerotic plaque, whereas a narrowed luminal artery, wall thickening with irregular inner margin, without enhancement nor hemorrhagic component, these vessel wall imaging criteria point out to inactivity (non-vulnerability) of atherosclerotic plaque.

These results were in agreement (as regard to intracranial atherosclerosis and vasculitis) with those obtained by 


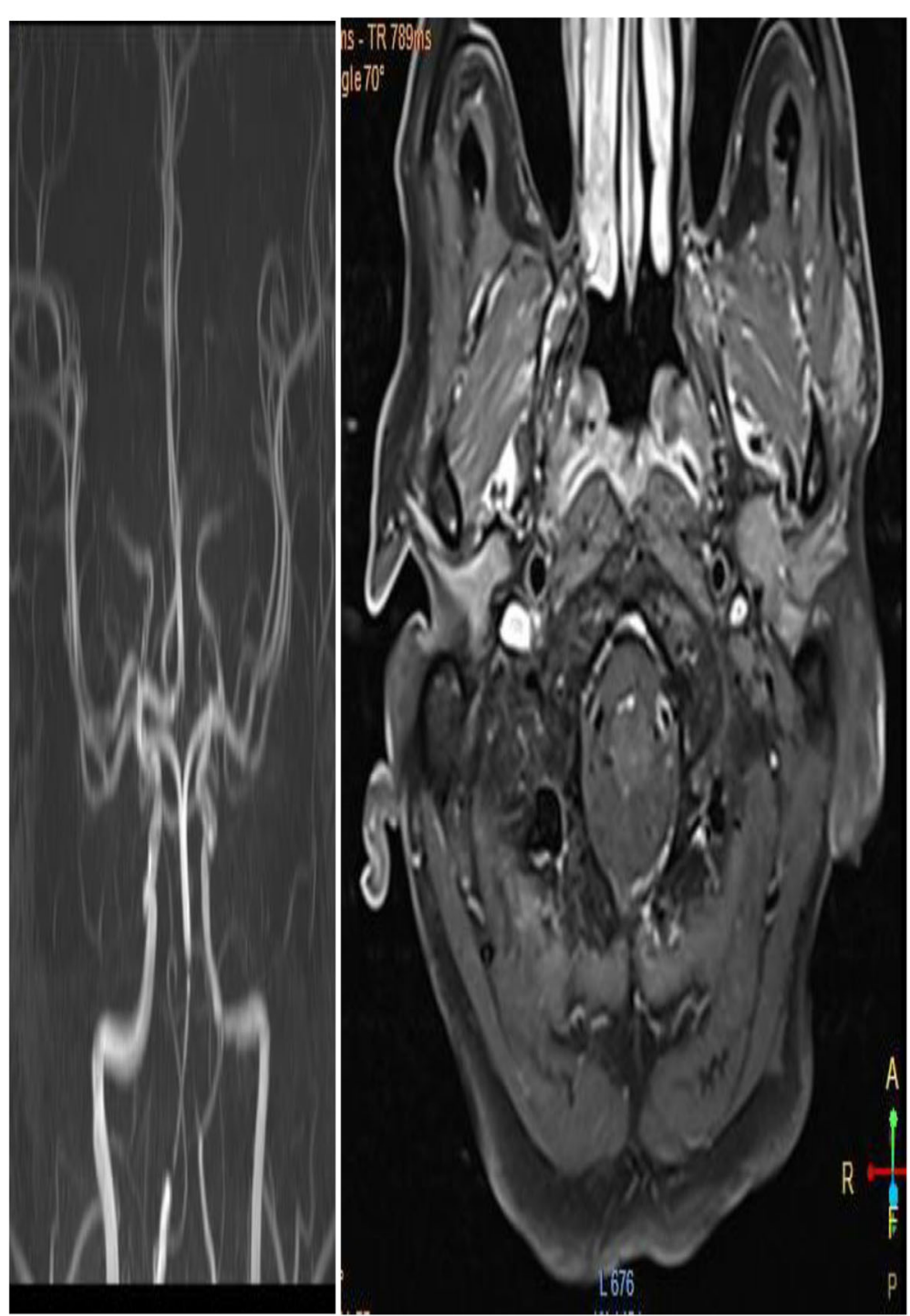

Fig. 3 MRA that shows remarkable narrowing of both vertebral arteries especially the left one (a). MR vessel wall imaging (T1 post-contrast) shows narrowed vertebral arteries, lumen, and irregular wall thickening with the left one showing eccentric enhancement which denotes atherosclerotic active plaque (b)

Mossa-Basha and colleagues in 2015 who found that the presence of eccentric wall involvement, diffuse, heterogeneous, or focal lesion enhancement are all characteristics that can reliably identify intracranial atherosclerosis, whereas diffuse, homogeneous, circumferential lesion enhancement is most common with vasculitis [8].
Our results are also in agreement with the literature reported by Mandell and colleagues in 2017 who found that vessel wall MR imaging of intracranial atherosclerotic plaque typically demonstrates arterial wall thickening, which eccentrically (nonuniformly) involves the circumference of the arterial wall, whereas vessel wall

Table 5 Comparison between MRA and MR vessel wall imaging in the ability to detect vulnerability in cases of intracranial atherosclerosis

\begin{tabular}{|c|c|c|c|c|c|}
\hline \multirow{3}{*}{$\begin{array}{l}\text { Plaque activity (vulnerability) } \\
\text { in the case of atherosclerosis }\end{array}$} & & \multicolumn{4}{|c|}{ Magnetic resonance vessel wall imaging } \\
\hline & & \multicolumn{2}{|l|}{ Yes } & \multicolumn{2}{|l|}{ No } \\
\hline & & Count & $\%$ & Count & $\%$ \\
\hline \multirow[t]{2}{*}{ Magnetic resonance angiography } & Yes & 0 & 0 & 0 & 0 \\
\hline & No & 11 & 100 & 0 & 0 \\
\hline
\end{tabular}


Table 6 Summary for vessel wall MR imaging criteria for different intracranial vasculopathies in the cases studied

\begin{tabular}{lllll}
\hline $\begin{array}{l}\text { Intracranial } \\
\text { vasculopathies }\end{array}$ & $\begin{array}{l}\text { Vulnerable Intracranial } \\
\text { atherosclerosis }\end{array}$ & $\begin{array}{l}\text { Non-vulnerable intracranial } \\
\text { atherosclerosis }\end{array}$ & $\begin{array}{l}\text { Central nervous } \\
\text { system vasculitis }\end{array}$ & Moyamoya disease \\
\hline $\begin{array}{l}\text { Features on vessel } \\
\text { wall MR imaging }\end{array}$ & $\begin{array}{l}\text { A narrowed luminal artery, } \\
\text { wall thickening with irregular } \\
\text { inner margin, eccentric (non- } \\
\text { uniformly) enhancement or } \\
\text { hemorrhagic component. }\end{array}$ & $\begin{array}{l}\text { A narrowed luminal artery, wall } \\
\text { thickening with irregular inner } \\
\text { margin, without enhancement } \\
\text { nor hemorrhagic component. }\end{array}$ & $\begin{array}{l}\text { Circumferential } \\
\text { (uniformly) wall } \\
\text { enhancement with } \\
\text { regular smooth inner } \\
\text { margin. }\end{array}$ & $\begin{array}{l}\text { Narrowing of luminal artery } \\
\text { without post-contrast } \\
\text { enhancement of the wall, } \\
\text { no hemorrhagic nor fatty } \\
\text { content. }\end{array}$ \\
$\begin{array}{l}\text { Number of the } \\
\text { studied cases }\end{array}$ & 8 cases & 3 cases & 3 cases & 2 cases \\
\hline
\end{tabular}

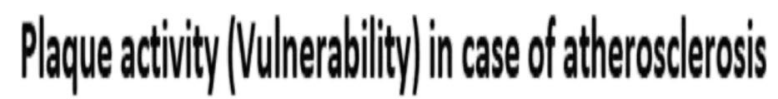
|MRressel wal imaginge|

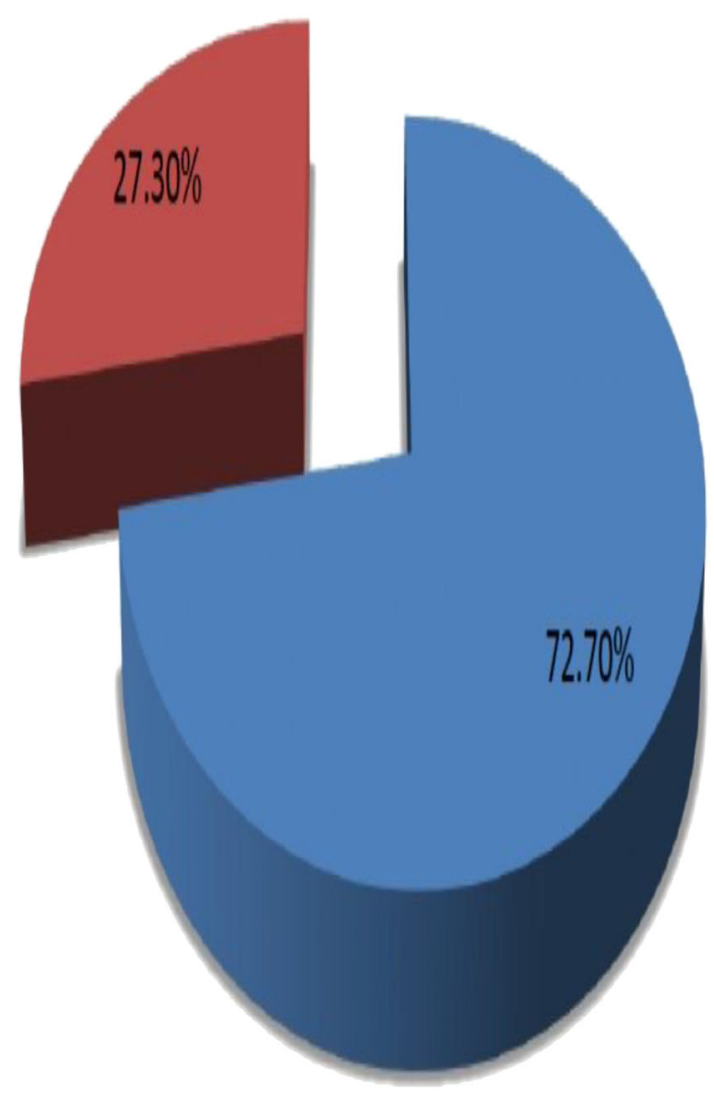

\section{Ivunerable Inonvwherable}

Fig. 4 Vulnerable vs non-vulnerable prevalence among the intracranial atherosclerotic group
MR imaging often demonstrates smooth, homogeneous, concentric arterial wall thickening and enhancement in patients with CNS vasculitis [2].

Regarding vasculitis, the results of the study done by Obusez and his colleagues in 2014 that involved thirteen patients with CNS vasculitis, our results agreed with 9 patients who showed smooth, concentric wall enhancement and thickening, in disagreement with 3 patients which had smooth, eccentric wall enhancement and thickening and 1 patient was without wall enhancement and thickening [9].

Also as regards vasculitis, similar findings were reported by Mandell and colleagues in 2012 who used vessel wall MRI to differentiate between reversible cerebral vasoconstriction syndrome and central nervous system vasculitis. In cases of CNS vasculitis, vessel wall MRI demonstrated circumferential arterial wall thickening and enhancement [10].

Also as regards plaque activity (vulnerability), nearly similar findings were reported by Vergouwen and colleagues in 2011. In his study, eight patients were identified to characterize the vessel wall imaging findings and enhancement patterns in the middle cerebral artery of patients with presumed atherosclerotic disease and recent infarction in the territory of the affected artery using 3-T MRI: 6 patients had an eccentric M1 stenosis, 1 had an eccentric proximal M2 stenosis, and 1 had a distal M2 stenosis with inconclusive eccentricity. Enhancement of the lesion was observed in all patients who underwent scanning within 5 months of the index event. Four intracranial atherosclerotic plaques were found in asymptomatic vessels, and none of these had enhancement. Vessel wall MR imaging is considered anatomical assessment of vessel wall pathology which is different from other modalities which considered functional assessment as transcranial duplex [11].

Our study had some limitations because of a small sample size and other modalities of intracranial imaging (as computed tomography angiography) were not done. Larger studies are recommended to detect the reliability of vessel wall MR imaging in assessment of atherosclerotic plaque activity. 


\section{Conclusion}

Vessel wall MR imaging is considered a useful tool to stroke patients with suspected intracranial large vessel atherosclerosis seen in MRA to assess atherosclerotic plaque activity and characterization of stenotic lesions that have already been detected with common angiographic methods.

\section{Abbreviations}

MRI: Magnetic resonance imaging; CTA: Computed tomography angiography; MRA: Magnetic resonance angiography; ICAD: Intracranial atherosclerotic; SPSS: Statistical package for the social sciences

\section{Acknowledgements}

Not applicable

\section{Authors' contributions}

SF, HZ, YA, and AS conceived of the study and participated in its design and coordination and helped to draft the manuscript. MK and KA participated in the design of the study and performed the statistical analysis. The authors have read and approved the manuscript.

\section{Funding}

Not applicable

\section{Availability of data and materials}

Dataset is available as the master sheet in Excel format and publicly available in the Neurology Department, Ain Shams University, by communicating with the corresponding author.

\section{Ethics approval and consent to participate}

The study protocol was approved by the Ain Shams University, Faculty of Medicine Research Ethics Committee FWA 000017585 in January 2016. Written informed consent was obtained from the patients participating in the study.

\section{Consent for publication}

Not applicable

\section{Competing interests}

All authors declare that they do not have any competing interests.

\section{Author details}

${ }^{1}$ Neurology Department, Ain Shams University, 19/1/42 Elrehab City, Cairo

11841, Egypt. ${ }^{2}$ Radiology Department, Ain Shams University, Cairo, Egypt.

Received: 3 July 2020 Accepted: 3 November 2020

Published online: 09 December 2020

\section{References}

1. Alexander MD, Yuan C, Rutman A, Tirschwell DL, Palagallo G, Gandhi D, et al. High-resolution intracranial vessel wall imaging: imaging beyond the lumen. J Neurol Neurosurg Psychiat. 2016;87(6):589-97.

2. Mandell DM, Mossa-Basha M, Qiao Y, Hess CP, Hui F, Matouk C, et al. Intracranial vessel wall MRI: principles and expert consensus recommendations of the American society of neuroradiology. AJNR Am J Neuroradiol. 2017;38(2):218-29.

3. Lindenholz A, van der Kolk AG, Zwanenburg JJ, Hendrikse J. The use and pitfalls of intracranial vessel wall imaging: how we do it. Radiology. 2017; 286(1):12-28.

4. Den Hartog AG, Bovens SM, Koning W, Hendrikse J, Luijten PR, Moll FL, et al. Current status of clinical magnetic resonance imaging for plaque characterisation in patients with carotid artery stenosis. Eur J Vasc Endovasc Surg. 2013;45(1):7-21.

5. Andre JB, Bresnahan BW, Mossa-Basha M, Hoff MN, Smith CP, Anzai Y, et al. Toward quantifying the prevalence, severity, and cost associated with patient motion during clinical MR examinations. J Am Coll Radiol. 2015;12 689-95.
6. Chan YH. Biostatistics 102: quantitative data-parametric \& non-parametric tests. Singapore Med J. 2003a;44(8):391-6.

7. Chan YH. Biostatistics 103: qualitative data-tests of independence. Singapore Med J. 2003b:44(10):498-503.

8. Mossa-Basha M, Hwang WD, De Havenon A, Hippe D, Balu N, Becker KJ, et al. Multicontrast high-resolution vessel wall magnetic resonance imaging and its value in differentiating intracranial vasculopathic processes. Stroke. 2015:46(6):1567-73.

9. Obusez EC, Hui F, Hajj-Ali RA, Cerejo R, Calabrese LH, Hammad T, Jones SE. High-resolution MRI vessel wall imaging: spatial and temporal patterns of reversible cerebral vasoconstriction syndrome and central nervous system vasculitis. AJNR Am J Neuroradiol. 2014;35(8):1527-32.

10. Mandell DM, Matouk CC, Farb RI, Krings T, Agid R, TerBrugge $K$, et al. Vessel wall MRI to differentiate between reversible cerebral vasoconstriction syndrome and central nervous system vasculitis: preliminary results. Stroke. 2012;43(3):860-2.

11. Vergouwen MD, Silver FL, Mandell DM, Mikulis DJ, Swartz RH. Eccentric narrowing and enhancement of symptomatic middle cerebral artery stenoses in patients with recent ischemic stroke. Arch Neurol. 2011;68(3): 338-42. https://doi.org/10.1001/archneurol.2011.20.

\section{Publisher's Note}

Springer Nature remains neutral with regard to jurisdictional claims in published maps and institutional affiliations.

\section{Submit your manuscript to a SpringerOpen ${ }^{\circ}$ journal and benefit from:}

- Convenient online submission

- Rigorous peer review

- Open access: articles freely available online

- High visibility within the field

- Retaining the copyright to your article

Submit your next manuscript at $\boldsymbol{\nabla}$ springeropen.com 